\title{
Modelling Work Effort of Workers in the Crowdsourcing Intermediary Market
}

\author{
Ying Liu \\ Changsha University of Science \\ \&Technology \\ mosorg@163.com
}

\author{
Yongmei Liu \\ Central South University \\ liuyongmeicn@163.com
}

\author{
Bo Sophia Xiao \\ University of Hawaii at Manoa \\ boxiao@hawaii.edu
}

\begin{abstract}
This study examines crowdsourcing task characteristics (skill variety, task identity, task significance, autonomy, feedback, and task clarity) and the online work situation factor; that is, the trust in evaluations on work effort in the crowdsourcing intermediary market. An e-questionnaire was released as a crowdsourcing task on the Time Fortune website in China; data from 231 valid questionnaires were analyzed using SmartPLS 3 software. Results show that under the conditions of this study, crowdsourcing workers' internal motivation has a significant positive relationship with their effort. Task autonomy and feedback have significant and positive relationship with internal motivation. Skill variety, task significance, task clarity, and task identity have no significant correlation with internal motivation. However, task clarity has a significant and positive relationship with work effort. The study also finds that the effect of workers' trust in the task requester on work effort is mediated by internal motivation.
\end{abstract}

\section{Introduction}

Since Howe[1] proposed the concept of crowdsourcing, it has been widely used in various fields of the internet economy and has taken many forms as an online distributed problem solving and production model[2], including crowdfunding, creative crowdsourcing, and crowdsourcing intermediary market, among others. The crowdsourcing intermediary market has gained much attention due to its enormous economic and social value. According to Kaganer, et al. [3], the crowdsourcing intermediary market is an "artificial cloud platform" that connect task requesters to workers to for online service transactions. It can be divided into four operating modes: Facilitator, Arbitrator, Aggregator, and Governor [3]. This study focuses on the Arbitrator model, where workers participate in the crowdsourcing task through competition or contest. InnoCentive and the Time Fortune website are typical representatives of this model.

In the competitive crowdsourcing intermediary market, after the task requester releases the crowdsourcing task, many workers submit solutions. However only a few or, even, one worker will win. In such a highly competitive environment, the probability of winning is often low. Thus, workers may not want to spend time and energy to complete crowdsourcing work. Moreover, because of the lack of formal obligations in the crowdsourcing intermediary market, it is difficult for task requesters to enforce work effort [4]. Because effort is related to work performance[5], crowdsourcing workers' effort is an important issue worthy of attention.

Sun, et al. [6] proposed that return valence, trust in the task requester, and self-performance are important antecedents that influence work effort. Liang, et al [4] used a mediated moderator model to examine the interactive effect of internal motivation and external motivation on work effort. Bockstedta, et al. [7] examined the impact of individual diversity in innovation competitions on work effort. Most of these studies explain the work effort behavior from an individual motivation or national culture perspective. They fail to explain the crowdsourcing work effort from the perspective of crowdsourcing work characteristics.

Many studies on the traditional job characteristics model suggest that internal and external motivations are important predictors of increased work effort[8].This study focus on the association between internal motivation with crowdsourcing workers' effort. According to Eby, et al. [9], the formation of internal motivation are related to the job characteristics and the working environment. Therefore, the job 
characteristics model is significant in explaining internal motivation [10].

The crowdsourcing intermediary market is a webbased online labor market with electronization and virtualization as typical features. In this environment, task clarity is considered to be an important factor predicting effort[11]. Due to the lack of direct communication, crowdsourcing workers rely on the task information posted by the task requester to understand the specific job requirements [12]. The lack of clarity can reduce worker performance and, ultimately, the work quality [13]. Therefore, the study incorporates task clarity into the job characteristics model and attempt to explore its relationship with internal motivation and effort.

Moreover, since there is no legal labor contract, crowdsourcing workers can enter or exit the market at any time [14] and, decide their level of effort. In this highly uncertain work environment, trust between transaction parties is particularly important. Therefore, trust in the task requester is a crucial work situation factor. Related research also shows that trust is an antecedent variable that increases participation and work effort [6]. In summary, this study explains the workers' work effort behavior from the perspective of crowdsourcing work characteristics and the online work situation.

\section{Literature review}

\subsection{Job characteristic model}

The job characteristics model was proposed by Hackman \& Oldham [15]. The model posits that five core job characteristics (including skill variety, task identity, task significance, autonomy, and feedback) have an important impact on employee behavior and attitude outcomes by influencing three psychological states of perceived work meaningfulness, work responsibility, and the knowledge of work results. Given these psychological states, employees would be internally motivated to perform better [16]. The significant effect of job characteristics on internal work motivation has been verified in industrial sales, hotel work and online knowledge sharing.

Different from the traditional work situation, workers in the crowdsourcing intermediary market can freely participate in and withdraw from tasks, which have high mobility [14]. Meanwhile, in the competitive market, there is great uncertainty on whether workers will win and get paid [17]. These unique working mechanisms may weaken the explanatory power of the job characteristics theory. For example, some platforms do not provide sufficient skill diversity, task identity, and task significance, leading to low job motivation, performance, and satisfaction [14]. Other scholars propose that task clarity is important and has association with job performance and satisfaction [18]. Given the remote working context, the degree to which tasks are clearly defined is an important antecedent variable predicting work performance and effort [11]. Different from the traditional work situation, the crowdsourcing intermediary market is a virtual work market, which has the essential characteristics of remote work. Task clarity is an important crowdsourcing work feature [13]. Given virtualization, this study incorporates task clarity into the traditional work characteristic model and try to explore its correlation with internal motivation and work effort.

\subsection{Trust Theory}

Due to the high complexity and anonymity of the electronic trading market, sellers may exhibit unpredictable behaviors, causing customers to be unsure of current online risks and its full consequences [19]. Therefore, trust in the seller helps the consumer accept any risk associated with the transaction[20].

The crowdsourcing intermediary market also has typical characteristics of virtual trading markets such as uncertainty, anonymity, lack of control and potential opportunism [21]. Unlike traditional e-commerce, the crowdsourcing market is a reverse trading model where the task requester buys the service and the worker provides the service. Whether the worker ultimately wins depends on the subjective decision-making of the task requester. This situation makes it very uncertain for workers to get paid after submitting a solution. In this uncertain work environment, effort may have strong correlation with trust in the task requester. Some studies have verified the importance of trust in the crowdsourcing intermediary market[22]. Therefore, this study incorporates trust in the model and attempts to explore its relationship with work effort.

\section{Hypothesis development}

\subsection{Intrinsic motivation and work effort}

According to resource allocation theory, effort is considered to be a source of attention [23], and the different ways in which workers allocate resources to their tasks affect their performance [24]. Studies have shown that the degree of difference in employee work effort can be explained by the work motivation that drives employees [8]: internal motivation and external motivation have positive relationship with the employees' work effort. The competitive working 
mechanism requires workers to invest a certain amount of time and energy in advance. Therefore, whether the worker wins is inseparable from the extent of the effort invested. According to Kanfer [25], individuals who are internally motivated have an intrinsic pursuit of personal growth and development, autonomy, and competence, thus strengthening the level of their work effort. Therefore, workers with stronger internal motivations show stronger work effort. Hence, the following hypothesis is made:

Hypothesis 1: Crowdsourcing workers' internal motivation has a positive relationship with their work effort.

\subsection{Crowdsourcing work characteristics and intrinsic motivation}

3.2.1. Skill variety and internal motivation. The skill variety of crowdsourcing work is the degree to which workers use a variety of different skills and complete many different activities in the process of participating in crowdsourcing work [26]. When a task requires individuals to engage in activities that challenge or extend their skills and abilities, the individuals may experience personal meaning [15]. The crowdsourcing intermediary market is a service trading platform that connects workers with different experiences, abilities, skills to task requesters with different service requirements. Workers can choose to participate in crowdsourcing tasks according to their skills and competencies. Different tasks allow workers to apply different knowledge and skills that challenge them; thus, they will perceive the work as interesting and pleasant. Hence, the following hypothesis is formed:

Hypothesis 2: Skill variety has a positive relationship with workers' internal motivation.

3.2.2. Crowdsourcing task identity and internal motivation. According to Rousseau [27], task identity is the degree to which a holistic and identifiable work is completed. Hackman [28] believes that a job that includes a complete task, such as providing a complete service unit or providing a complete product, will always be more interesting and motivating than providing a fraction of the task. Currently, the tasks issued by task requesters are mainly logo design, copywriting, software development, among others. These tasks require workers to provide complete logo design pictures, manuscripts, or software development codes as final submissions. Therefore, the work involved in the crowdsourcing intermediary market has a high degree of independence and identifiability, the identity of which will positively contribute to workers' internal motivation. Therefore, the following assumption is made:
Hypothesis 3: Crowdsourcing task identity has a positive relationship with workers' internal motivation.

\subsubsection{Crowdsourcing task significance and internal} motivation. According to Rousseau [27], task significance is the extent to which work affects other's work or life. Hackman [28] also suggests that individuals can experience more meaning from work that can affect the physical or mental health of others, and are thus more internally motivated to work. Task significance motivates employees to complete their work by making employees feel the meaningfulness of the work. Since the reward of crowdsourcing tasks in the crowdsourcing market are relatively low, most workers use crowdsourcing task as part-time jobs to earn extra income or improve work skills. Therefore, for many crowdsourcing workers, the work has little impact on their lives and is of minor importance. Therefore, the following assumption is made:

Hypothesis 4: Crowdsourcing job significance has no significant relationship with workers' internal motivation.

3.2.4. Crowdsourcing task autonomy and internal motivation. Crowdsourcing work autonomy is the degree to which workers can freely complete tasks and submit solutions [26]. When a crowdsourcing task has a high degree of autonomy, work results will gradually depend on individual efforts, motivation, and decisionmaking rather than on the work manual or instructions from the boss [15]. Therefore, higher autonomy tasks can induce a higher sense of responsibility to internally motivate workers to complete their task. Given the openness of the market, workers can freely enter or exit crowdsourcing tasks. Workers have complete autonomy in task selection and work method. According to Malone \& Lepper [29], a higher level of self-control will mean a higher internal motivation. Hence, the following hypothesis is formed:

Hypothesis 5: Crowdsourcing task autonomy has a positive relationship with workers' internal motivation.

3.2.5. Crowdsourcing task feedback and internal motivation. Feedback is the degree of understanding the quality of personal work completion [27]. Crowdsourcing task feedback refers to the information workers get from task requesters about their work performance. Studies show that positive feedback can increase internal motivation by improving the sense of competence, while negative feedback on perceived competence can weaken internal and external motivation, resulting in no motivation [10]. Many platforms provide task requesters with function to provide feedback on worker solutions. After submitting the solution, if workers receive feedback from task 
requesters on their solutions, they will perceive that their solution is appreciated, and thus, experience the value of their work. This perception of the value of their work would increase their internal motivation. Hence, the following hypothesis is formed:

Hypothesis 6: Crowdsourcing task feedback has a positive relationship with workers' internal motivation.

\subsection{Task clarity, internal motivation and work effort}

3.3.1. Task clarity and internal motivation. The task in the crowdsourcing intermediary market is, by nature telework. Task clarity refers to the existence of clear criteria standards for how tasks are performed and the exact results required [30]. Task clarity is a crucial concept in the digital media workplace, which lacks physical space and face-to-face communication [31]. Kim [32] believes that individuals are motivated not only by intrinsic needs but also by positive job-related factors, such as task clarity, skill utilization, task significance, and social interaction. Tasks with clear and detailed instructions will make workers have the confidence to complete the task, thus, increasing their expectation of winning. Workers will be internally motivated and willing to participate in the task; Contrarily, if work instructions are vague, workers will lose the confidence to complete the task because of the lack of clarity, thus, reducing their expectation of winning and their willingness to participate in the task. Hence, the following hypothesis is formed:

Hypothesis 7: Crowdsourcing task clarity has a positive relationship with workers' internal motivation.

3.3.2. Task clarity and work effort. According to organizational psychology research, task clarity generally includes goal clarity and role clarity. Goal clarity refers to the clarity of one's objectives and responsibilities [33], while role clarity represents clear working procedures, standards and knowledge of results[34]. Gadiraju et al. (2017) proposed that task clarity is an important feature of crowdsourcing work, which will enhance workers' performance.

In the competitive crowdsourcing intermediary market, the tasks are mainly logo design, advertising design, software development and among others. The effective completion of these tasks requires workers to understand the specific details and requirements of tasks fully. When the description of the task requirement information is relatively clear, the worker will more easily understand the specific requirements of the task requester for the submission. Thus, the solution will be more in line with the criteria of the task requester. Hence, the worker will be more willing to complete the task; When the task requirement information is vague, it is difficult for the worker to understand the specific work requirements, and the quality of the solution will be far from the requirements of the task requester, thus reducing worker's work effort. Therefore, the following assumption is made:

Hypothesis 8: Crowdsourcing task clarity has a positive relationship with work effort.

\subsection{Trust in the task requester, internal motivation and work effort}

3.4.1. Trust in the task requester and internal motivation. Dirks \& Ferrin [35] argued that trust would directly impact on many employee outcomes, such as attitude and performance. Other studies show that trust also has a direct impact on internal motivation. Chen, et al. [36] proposed that public managers' trust in citizens, colleagues, and institutional leaders can enhance their motivation for public service. This study hypothesizes that trust in the task requester would have a positive relationship with workers' internal motivation; that is, when workers show trust in the task requester, they will be internally motivated to participate in crowdsourcing tasks. Contrarily, if workers distrust task requesters, their internal motivation to participate in crowdsourcing tasks will reduce. Hence, the following hypothesis is formed:

Hypothesis 9: Crowdsourcing workers' trust in task requester has a positive relationship with internal motivation.

3.4.2. Trust in the task requester and work effort. According to Pavlou \& Gefen [37], trust in the task requester is a subjective belief that the transaction takes place in a manner consistent with their expectation of trustworthy behavior. The competitive crowdsourcing intermediary market requires workers to invest time and energy to submit solutions in advance; whether workers can get paid ultimately depends on whether the task requester will keep their promises [6]. When workers expect task requesters to review their solution carefully to have a chance to win, they will be motivated to put more effort into the submission. Contrarily, if workers distrust the task requester (that is, they don't believe the task requester would evaluate their solution carefully, and their chance of winning is low), they will decrease their work effort. Hence, the following hypothesis is formed:

Hypothesis 10: Crowdsourcing workers' trust in task requester has a positive relationship with work effort.

In short, this study integrated the job characteristics model, motivation theory, and trust theory to build the theoretical model, as shown in Figure 1. 


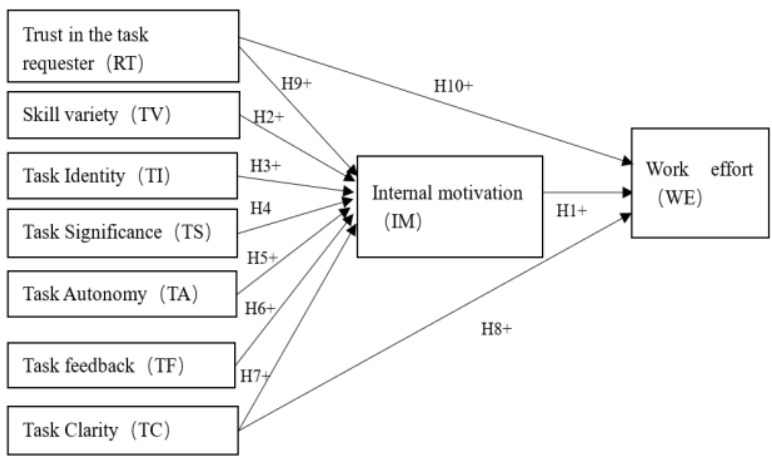

Figure 1. Theoretical model

\section{Research method}

\subsection{Pre-test and small-scale test}

The initial questionnaire employed was determined using the literature review and submitted to five doctoral students in management for review, from which the questionnaire was revised to further adapt it to the crowdsourcing intermediary market. Next, the "questionnaire star" website (www.wjx.cn) was employed to generate the electronic questionnaire and was released to the Time Fortune website (www.680.com) in the form of an online task. Workers were recruited to complete the questionnaire. For each questionnaire, $4 \mathrm{RMB}$ will be paid. After collecting 50 electronic questionnaires, following the reliability and validity, some questionnaire items were readjusted. Finally, the measurement scale was determined (see Appendix A).

\subsection{Data collection}

Subsequently, the electronic questionnaire continued to be released in the Time Fortune website. The Time Fortune website was established in September 2006; it is an industry-leading crowdsourcing intermediary website in China. As of January 2019, the website's homepage showed a total amount of 3,070,010,347 RMB in real-time transactions. The crowdsourcing tasks of the Time Fortune website include logo design, decoration design, marketing communication, software development, among others. The main groups are college students and in-service staff, and most of them work part-time.

The questionnaire was released from October 2018 to November 2018. A total of 231 complete questionnaires were received. Table 1 describes the statistical characteristics of responders.
Table 1. Demographic profile

\begin{tabular}{|c|c|c|c|}
\hline & Characteristic & Frequency & Percent \\
\hline \multirow[t]{2}{*}{ Gender } & \multirow{2}{*}{$\begin{array}{l}\text { Male } \\
\text { Female }\end{array}$} & 146 & 63.2 \\
\hline & & 85 & 36.8 \\
\hline \multirow[t]{4}{*}{ Education } & High school or below & 29 & 12.6 \\
\hline & College & 83 & 35.9 \\
\hline & University & 115 & 49.8 \\
\hline & Graduate school or above & 4 & 1.7 \\
\hline \multirow[t]{5}{*}{ Tenure } & $0 \sim 0.5$ year & 43 & 18.6 \\
\hline & $0.5 \sim 1$ year & 53 & 22.9 \\
\hline & $1 \sim 2$ year & 57 & 24.7 \\
\hline & $3 \sim 5$ year & 54 & 23.4 \\
\hline & 5 years and above & 24 & 10.4 \\
\hline \multirow{5}{*}{$\begin{array}{l}\text { Task types that } \\
\text { participate } \\
\text { mostly }\end{array}$} & \multirow{5}{*}{$\begin{array}{l}\text { Design } \\
\text { Website and program } \\
\text { development } \\
\text { Advertisement writing } \\
\text { Copywriting } \\
\text { Online Marketing } \\
\text { Others }\end{array}$} & 13 & 5.6 \\
\hline & & 11 & 4.8 \\
\hline & & 62 & 26.8 \\
\hline & & 114 & 49.4 \\
\hline & & 31 & 13.4 \\
\hline
\end{tabular}

\subsection{Measurement}

The scales adopted in this study are all mature scales and are appropriately adjusted and adapted to the crowdsourcing market. Skill variety (TV), task identity (TI), task significance (TS), task autonomy (TA) and task feedback (TF) were measured using the job diagnostic scale (JDS) developed by Hackman \& Oldham [38]. The measurement of internal motivation (IM) is made by Liang, et al [4]. Trust in the task requester (RT) was measured using the scale of trust in the community seller used by Pavlou \& Gefen [37]. Task clarity (TC) was measured using the task clarity scale used by Kirkpatrick \& Locke [39]. The work effort (WE) measure developed by Liang, et al [4] was adopted to measure work effort. A seven-point Likert scale was employed (from 1, strongly disagree, to 7 , strongly agree).

\subsection{Common method variance}

This study utilizes SmartPLS 3 software for data analysis. In this study, multiple variable data are often provided by the same subject. Thus, it is necessary to conduct common method variance test to ensure that no systematic deviation affects the data. According to Liang, et al. [40], the PLS method is used to evaluate the common method bias. The results show that the average variance interpreted by the substantive indicators is 0.630 , while the average variance interpreted by the method-based indicators is 0.012 . Moreover, most method factor loadings are insignificant. Given that the common method variance is small and insignificant, there is no serious common method variance in the data employed. 


\section{Results}

\subsection{Construct validity and reliability test}

In PLS-SEM, the reliability of constructs can be evaluated by combining reliability (CR) values. As shown in Table 2, CR values of all reflective constructs were greater than 0.8 , and higher than the minimum requirement of 0.7 , indicating that these scales had good internal consistency. The scale's convergent validity can be tested by factor loading and average variance extracted (AVE) values. In Table 2, all the factor loadings are higher than 0.7. Meanwhile, the AVE values of all reflective constructs were higher than 0.56 , meeting the recommended criteria.

Fornell-Larcker Criterion commonly test the reflective measurement model's discriminant validity. According to Table 3, the Fornel-Larcker criterion indicates that off-diagonal values represent correlation coefficients between potential constructs, while diagonal values represent the square root of the AVE value of each construct. The data show that there is good discriminant validity among the constructs in the model.

\subsection{Structural model}

First, the structural model's collinearity is tested. The data shows that the variance inflation factor (VIF) value among all constructs is $<5$, indicating that there was no severe collinearity among constructs.

Table 2. Construct reliability and validity

\begin{tabular}{|c|c|c|c|c|}
\hline Construct & Item & Item Loading & $\mathrm{CR}$ & AVE \\
\hline \multirow[t]{4}{*}{ Internal motivation (IM) } & IM1 & 0.771 & 0.844 & 0.575 \\
\hline & $\mathrm{IM} 2$ & 0.734 & & \\
\hline & IM3 & 0.797 & & \\
\hline & IM4 & 0.724 & & \\
\hline \multirow[t]{4}{*}{ Task Clarity (TC) } & TC1 & 0.755 & 0.865 & 0.617 \\
\hline & $\mathrm{TC} 2$ & 0.731 & & \\
\hline & TC3 & 0.827 & & \\
\hline & TC4 & 0.826 & & \\
\hline \multirow[t]{2}{*}{ Skill Variety（TV） } & TV1 & 0.827 & 0.854 & 0.746 \\
\hline & TV2 & 0.898 & & \\
\hline \multirow[t]{3}{*}{ Task Significance (TS) } & TS1 & 0.828 & 0.844 & 0.643 \\
\hline & TS2 & 0.769 & & \\
\hline & TS3 & 0.808 & & \\
\hline \multirow[t]{3}{*}{ Task Identity（TI） } & TI1 & 0.847 & 0.845 & 0.646 \\
\hline & TI2 & 0.779 & & \\
\hline & TI3 & 0.783 & & \\
\hline \multirow[t]{3}{*}{ Task Autonomy (TA) } & TA1 & 0.820 & 0.866 & 0.683 \\
\hline & TA2 & 0.871 & & \\
\hline & TA3 & 0.786 & & \\
\hline \multirow[t]{3}{*}{ Task Feedback (TF) } & TF1 & 0.795 & 0.896 & 0.741 \\
\hline & TF2 & 0.887 & & \\
\hline & TF3 & 0.897 & & \\
\hline Trust in the task & RT1 & 0.798 & 0.895 & 0.681 \\
\hline \multirow[t]{3}{*}{ requester (RT) } & RT2 & 0.793 & & \\
\hline & RT3 & 0.866 & & \\
\hline & RT4 & 0.843 & & \\
\hline \multirow[t]{7}{*}{ Work effort (WE) } & WE1 & 0.782 & 0.901 & 0.566 \\
\hline & WE 2 & 0.730 & & \\
\hline & WE 3 & 0.774 & & \\
\hline & WE 4 & 0.722 & & \\
\hline & WE 5 & 0.727 & & \\
\hline & WE 6 & 0.740 & & \\
\hline & WE7 & 0.789 & & \\
\hline
\end{tabular}

Table 3 Discriminant validity

\begin{tabular}{lccccccccc}
\hline & IM & RT & TA & TC & TF & TI & TS & TV & WE \\
\hline IM & $\mathbf{0 . 7 5 8}$ & & & & & & & & \\
\hline RT & 0.695 & $\mathbf{0 . 8 2 6}$ & & & & & & & \\
\hline TA & 0.572 & 0.484 & $\mathbf{0 . 8 2 7}$ & & & & & & \\
\hline TC & 0.586 & 0.619 & 0.587 & $\mathbf{0 . 7 8 6}$ & & & & & \\
\hline TF & 0.582 & 0.533 & 0.514 & 0.474 & $\mathbf{0 . 8 6 1}$ & & & & \\
\hline TI & 0.579 & 0.544 & 0.640 & 0.628 & 0.616 & $\mathbf{0 . 8 0 3}$ & & & \\
\hline TS & 0.488 & 0.478 & 0.482 & 0.447 & 0.676 & 0.633 & $\mathbf{0 . 8 0 2}$ & & \\
\hline TV & 0.494 & 0.455 & 0.462 & 0.482 & 0.590 & 0.659 & 0.584 & $\mathbf{0 . 8 6 3}$ & \\
\hline WE & 0.693 & 0.623 & 0.571 & 0.706 & 0.430 & 0.636 & 0.450 & 0.536 & $\mathbf{0 . 7 5 2}$ \\
\hline $\begin{array}{l}\text { Note: internal motivation (IM), trust in task requester (RT), task clarity (TC), task autonomy (TA), } \\
\text { skill diversity (TV), task integrity (TI), task significance (TS), task feedback (TF), work effort (WE). }\end{array}$
\end{tabular}

Second, the Bootstrapping program was used for 5,000 repeated samples to evaluate the significance of the path coefficient. According to Table 5, the $\mathrm{P}$ values of TV -> IM, TS -> IM, TI -> IM, TC -> IM, and RT -> WE are all greater than 0.1 , and those of other paths are all less than 0.05 .

Third, the $\mathrm{R}^{2}$ values of endogenous latent variables in the path model are tested. As shown in Figure 2, $\mathrm{R}^{2}$ of work effort indicates that internal motivation, trust in task requester, and task clarity can predict $62.2 \%$ of the work effort. The $\mathrm{R}^{2}$ value of internal motivation indicates that skill diversity, work importance, work integrity, work autonomy, task clarity, feedback, and trust in the task requester can predict $59.3 \%$ of the variance of internal motivation.

Table 4 Hypothesis testing

\begin{tabular}{lcccccc}
\hline Hypothesis & Path & Coefficient & $\begin{array}{c}\text { Standard } \\
\text { deviation }\end{array}$ & T-value & P-value & Decision \\
\hline H1 & IM $>$ WE & 0.376 & 0.069 & 5.448 & $0.000^{* * *}$ & yes \\
H2 & TV > IM & 0.054 & 0.075 & 0.713 & 0.476 & not \\
H3 & TI - IM & 0.049 & 0.091 & 0.536 & 0.592 & not \\
H4 & TS $>$ IM & -0.019 & 0.069 & 0.273 & 0.785 & yes \\
H5 & TA > IM & 0.180 & 0.083 & 2.153 & $0.031^{* * *}$ & yes \\
H6 & TF $>$ IM & 0.175 & 0.083 & 2.124 & $0.034^{* * *}$ & yes \\
H7 & TC - > IM & 0.092 & 0.078 & 1.181 & 0.238 & not \\
H8 & TC $>$ WE & 0.425 & 0.064 & 6.609 & $0.000^{* * *}$ & yes \\
H9 & RT $>$ IM & 0.416 & 0.065 & 6.364 & $0.000^{* * *}$ & yes \\
H10 & RT $>$ WE & 0.099 & 0.079 & 1.247 & 0.213 & not \\
\hline
\end{tabular}

Note: $* * \mathrm{p}<0.05, * * * \mathrm{p}<0.001$

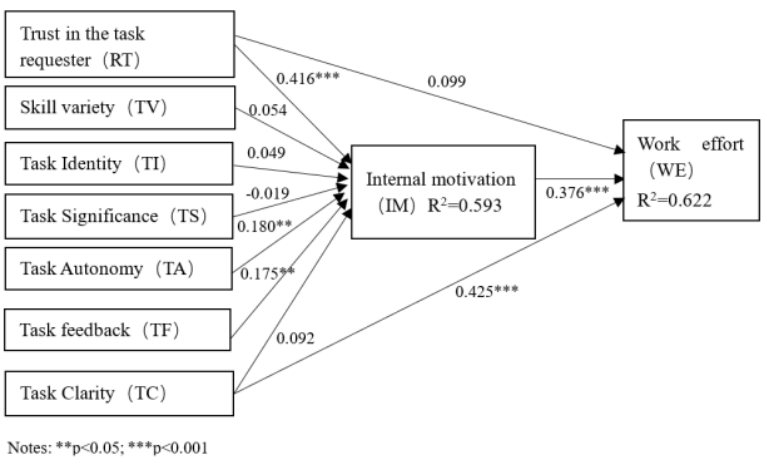

Figure 2. Results 
Finally, the study examined the mediating effect of IM between RT and WE, as well as TC and WE, respectively, to fully understand the relationship between various variables in the theoretical model. The mediating effect analysis program proposed by Hair Jr, et al. [41] was employed. The results show that the effect of workers' trust in the task requester on work effort is mediated by internal motivation.

\section{Conclusion}

\subsection{Theoretical contribution}

First, this study considers the virtual characteristics, regards work clarity as a supplement to the five characteristics of traditional work, and conducts an empirical test to explore its relationship with work effort. Under the conditions of this study, we observe a strong positive correlation between task clarity and work effort.

Second, this study explores the relationship between the situational factor of crowdsourcing work - trust in the task requester with work effort. Alcover \& Topa [42] argue that a shortcomings of traditional job characteristic model lies in its neglect of social and situational characteristics of work. This study observes that workers' trust in the task requester has a positive correlation with work effort under the conditions of this study. Moreover, this study finds the internal influencing mechanism of trust in the task requester on work effort. Therefore, this study supplement and expand of the job characteristic model.

Third, as observed by Hackman \& Oldham [15] and Zheng, et al [26], under the conditions of this study we observe a strong positive relationship between task autonomy, task feedback and internal motivation. However, unlike studies by Hackman \& Oldham [15], we find no relationship between skill variety, task identity, task significance and internal motivation under the conditions of this study. Therefore, this study is a further examination of the job characteristic model in the context of crowdsourcing intermediary market.

\subsection{Limitations and future research}

Firstly, this study only focuses on arbitrator crowdsourcing intermediary market. It is possible to further explore the effectiveness of the conclusions in other types of crowdsourcing intermediary markets.

Second, in addition to the traditional five job characteristics and task clarity, other job characteristics, such as task complexity [26] may also have relationship with work effort. Therefore, future studies can explore the relationship of other features with work effort.

Finally, although this study tentatively explores the effect of the work situational factor, the conclusion can be further extended. In addition to trust, perceived justice is also considered to as important [9]. Future research can further explore the relationship between perceived justice with work effort.

\section{Reference}

[1] J. Howe. "The Rise of Crowdsourcing[J]". Wired magazine, 2006, 14(6), pp. 1-4.

[2] D. C. Brabham. "Crowdsourcing as a Model for Problem Solving: An Introduction and Cases[J]". Convergence, 2008, 14(1), pp. 75-90.

[3] E. Kaganer, E. Carmel, R. Hirschheim, et al."Managing the Human Cloud[J]". MIT Sloan Management Review, 2013, 54(2), pp. 23-32.

[4] H. G. Liang, M. M. Wang, J. J. Wang, et al. "How Intrinsic Motivation and Extrinsic Incentives Affect Task Effort in Crowdsourcing Contests: A Mediated Moderation Model[J]". Computers in Human Behavior, 2018, 81, pp. 168-176.

[5] S. P. Brown, T. W. Leigh. "A New Look at Psychological Climate and Its Relationship to Job Involvement, Effort, and Performance[J]". Journal of applied psychology, 1996(No.4), pp. 358-368.

[6] Y. Q. Sun, N. Wang, C. X. Yin, et al."Understanding the Relationships between Motivators and Effort in Crowdsourcing Marketplaces: A Nonlinear Analysis[J]". International Journal of Information Management, 2015, 35(3), pp. 267-276.

[7] J. Bockstedta, C. Druehlb, A. Mishrab. "Problem-Solving Effort and Success in Innovation Contests: The Role of National Wealth and National Culture[J]". Journal of Operations Management, 2015, 36, pp. 187-200.

[8] A. Dysvik, B. Kuvaas. "Intrinsic and Extrinsic Motivation as Predictors of Work Effort: The Moderating Role of Achievement Goals[J]". British Journal of Social Psychology, 2013, 52(3), pp. 412-430.

[9] L. T. Eby, D. M. Freeman, M. C. Rush, et al."Motivational Bases of Affective Organizational Commitment: A Partial Test of an Integrative Theoretical Model[J]". Journal of Occupational and Organizational Psychology, 1999(4), pp. 463-483.

[10] M. Gagné, E. L. Deci. "Self-Determination Theory and Work Motivation[J]". Journal of organizational Behavior, 2005, 26(4), pp. 331-362.

[11] J. G. Caillier. "Do Role Clarity and Job Satisfaction Mediate the Relationship between Telework and Work Effort?[J]". International Journal of Public Administration, 
2014, 37(4), pp. 193-201.

[12] P. Pollok, D. Lüttgens, F. T. Piller."Attracting Solutions in Crowdsourcing Contests: The Role of Knowledge Distance, Identity Disclosure, and Seeker Status[J]". Research Policy, 2018, 48(1), pp. 98-114.

[13] U. Gadiraju, J. Yang, A. Bozzon. Clarity Is a Worthwhile Quality: On the Role of Task Clarity in Microtask Crowdsourcing[C]. in Proceedings of the 28th ACM Conference on Hypertext and Social Media. 2017. Baltimore, USA: ACM.

[14] A. Kittur, J. V. Nickerson, M. Bernstein, et al. The Future of Crowd Work[C]. in Proceedings of the 2013 conference on computer supported cooperative work. 2013. San Antonio, USA: ACM.

[15] J. R. Hackman, G. R. Oldham. "Motivation through the Design of Work: Test of a Theory[J]". Organizational behavior and human performance, 1976, 16(2), pp. 250-279.

[16] G. R. Oldham, J. R. Hackman. 'Not What It Was and Not What It Will Be: The Future of Job Design Research[J]". Journal of organizational Behavior, 2010, 31(2-3), pp. 463479.

[17] Y. Sun, Y. Fang, K. H. Lim. "Understanding Sustained Participation in Transactional Virtual Communities[J]". Decision Support Systems, 2012, 53(1), pp. 12-22.

[18] C. Fournier."The Salesperson's Role Clarity and Task Clarity in Direct Marketing: Impact of Personal and Organizational Variables[J]". Journal of Direct Marketing, 1996, 10(3), pp. 8-17.

[19] Y. D. Wang, H. H. Emurian."An Overview of Online Trust: Concepts, Elements, and Implications[J]". Computers in Human Behavior, 2005, 21(1), pp. 105-125.

[20] P. Mccole, E. Ramsey, J. Williams. "Trust Considerations on Attitudes Towards Online Purchasing: The Moderating Effect of Privacy and Security Concerns[J]". Journal of business research, 2010, 63(9), pp. 1018-1024.

[21] D. L. Hoffman, T. P. Novak, M. Peralta. "Building Consumer Trust Online[J]". Communications of the ACM, 1999, 42(4), pp. 80-85.

[22] J. Feller, P. Finnegan, J. Hayes, et al."“Orchestrating' Sustainable Crowdsourcing: A Characterisation of Solver Brokerages[J]". The Journal of Strategic Information Systems, 2012, 21(3), pp. 216-232.

[23] R. Kanfer, P. L. Ackerman. "Motivation and Cognitive Abilities: An Integrative/Aptitude-Treatment Interaction Approach to Skill Acquisition[J]". Journal of applied psychology, 1989, 74(4), pp. 657.

[24] G. B. Yeo, A. Neal."A Multilevel Analysis of Effort, Practice, and Performance: Effects; of Ability, Conscientiousness, and Goal Orientation[J]". Journal of applied psychology, 2004, 89(2), pp. 231.
[25] R. Kanfer."Motivation Theory and Industrial and Organizational Psychology[J]". Handbook of industrial and organizational psychology, 1990, 1(2), pp. 75-130.

[26] H. Zheng, D. Li, W. Hou. "Task Design, Motivation, and Participation in Crowdsourcing Contests[J]". International journal of electronic commerce, 2011, 15(4), pp. 57- 88.

[27] D. M. Rousseau. "Technological Differences in Job Characteristics, Employee Satisfaction, and Motivation: A Synthesis of Job Design Research and Sociotechnical Systems Theory[J]". Organizational behavior and human performance, 1977, 19(1), pp. 18-42.

[28] J. R. Hackman. "Work Redesign and Motivation[J]". Professional Psychology, 1980, 11(3), pp. 445.

[29] T. W. Malone, M. R. Lepper. Making Learning Fun: A Taxonomy of Intrinsic Motivations for Learning, in Aptitude, Learning and Instruction[M], in Conative and Affective Process Analysis, R.E.Snow and Farr, Editors. 1987, Erlbaum: Hilsdale.

[30] D. D. Frink, G. R. Ferris."Accountability, Impression Management, and Goal Setting in the Performance Evaluation Process[J]". Human relations, 1998, 51(10), pp. 1259-1283.

[31] X. N. Deng, K. D. Joshi. 'Why Individuals Participate in Micro-Task Crowdsourcing Work Environment: Revealing Crowdworkers' Perceptions[J]". Journal of the Association for Information Systems, 2016, 17(10), pp. 648-673.

[32] S. Kim. "Participative Management and Job Satisfaction: Lessons for Management Leadership[J]". Public Administration Review, 2002, 62(2), pp. 231-241.

[33] J. E. Sawyer."Goal and Process Clarity: Specification of Multiple Constructs of Role Ambiguity and a Structural Equation Model of Their Antecedents and Consequences[J]". Journal of applied psychology, 1992, 77(2), pp. 130.

[34] J. R. Rizzo, R. J. House, S. I. Lirtzman. "Role Conflict and Ambiguity in Complex Organizations[J]". Administrative science quarterly, 1970, pp. 150-163.

[35] K. T. Dirks, D. L. Ferrin. "The Role of Trust in Organizational Settings[J]". Organization Science, 2001, 12(4), pp. 450-467.

[36] C. A. Chen, C. W. Hsieh, D. Y. Chen. "Fostering Public Service Motivation through Workplace Trust: Evidence from Public Managers in Taiwan[J]". Public Administration, 2014, 92(4), pp. 954-973.

[37] P. A. Pavlou, D. Gefen."Building Effective Online Marketplaces with Institution-Based Trust[J]". Information systems research, 2004, 15(1), pp. 37-59.

[38] J. R. Hackman, G. R. Oldham. "The Job Diagnostic Survey: An Instrument for the Diagnosis of Jobs and the Evaluation of Job Redesign Projects[J]". JSAS Catalog of 
Selected Documents in Psychology, 1974, 4, pp. 1-84.

[39] S. A. Kirkpatrick, E. A. Locke."Direct and Indirect Effects of Three Core Charismatic Leadership Components on Performance and Attitudes[J]". Journal of applied psychology, 1996, 81(1), pp. 36-51.

[40] H. Liang, N. Saraf, Q. Hu, et al."Assimilation of Enterprise Systems: The Effect of Institutional Pressures and the Mediating Role of Top Management[J]". MIS Quarterly, 2007, 31(1), pp. 59-87.

[41] J. F. Hair Jr, G. T. M. Hult, C. Ringle, et al. A Primer on Partial Least Squares Structural Equation Modeling (PlsSem)[M]. 2016, Thousand Oks: Sage Publications.

[42] C.-M. Alcover, G. Topa."Work Characteristics, Motivational Orientations, Psychological Work Ability and Job Mobility Intentions of Older Workers[J]". PLoS ONE, 2018, 13(4), pp. 1-24.

\section{Acknowledgement:}

This work was supported by The National Social Science Fund of China (16CGL007). The project leader is Ying Liu.

\section{Appendix A: Questionnaire items}

\section{Skill Variety (TV)}

1 ) How much variety is there in your job on crowdsourcing intermediary platform? That is, to what extent does the job require you to do many different things at work, using a variety of your skills and talents?

2) The job on the crowdsourcing intermediary platform require me to use a number of complex or high-level skills.

3 ) The job on the crowdsourcing intermediary platform is quite simple and repetitive*.

\section{Task Identity (TI)}

1) To what extent does your job on the crowdsourcing intermediary platform involve doing a "whole" and identifiable piece of work? That is, are the jobs on the crowdsourcing intermediary platform a complete piece of work that has an obvious beginning and end? Or are they only a small part of the overall piece of work, which is finished by other people or by automatic machines?

2) The job on the crowdsourcing intermediary platform is arranged so that I do have the chance to do an entire piece of work from beginning to end.

3) The job on the crowdsourcing intermediary platform provides me the chance to completely finish the pieces of work I begin.

\section{Task significance (TS)}

1) In general, how significant or important is your job on the crowdsourcing intermediary platform? That is, are the results of your work likely to significantly affect the lives or well-being of other people?

2) This job on the crowdsourcing intermediary platform is one where a lot of other people can be affected by how well the work gets done.

3) This job on the crowdsourcing intermediary platform itself are not very significant or important in the broader scheme of things.

\section{Task Autonomy（TA）}

1) How much autonomy is there in your job on the crowdsourcing intermediary platform? That is, to what extent does your job permit you to decide on your own how to go about doing the work?

2) The job on the crowdsourcing intermediary platform denies me any chance to use my personal initiative or judgement in carrying out the work.

3) The job on the crowdsourcing intermediary platform gives me considerable opportunity for independence and freedom to how I do the work.

\section{Task Feedback (TF)}

1)To what extent do task requesters let you know how well you are doing on your job?

2) Task requesters on this job almost never give me any "feedback" about how well I am doing in my work.

3) Task requesters often let me know how well they think I am performing the job.

6. Task Clarity (TC)

1) I knew exactly what to do on tasks which I am participating in on the crowdsourcing intermediary platform.

2) I was not very sure how to do on tasks which I am participating in on the crowdsourcing intermediary platform.

3) I knew how I was supposed to do the tasks which I am participating in on the crowdsourcing intermediary platform.

4) I was not clear about how the tasks which I am participating in on the crowdsourcing intermediary platform were to be.

7. Intrinsic Motivation (IM)

1) Participating in the tasks on the crowdsourcing intermediary platform is very interesting.

2) The process of participating in the tasks on the crowdsourcing intermediary platform is very pleasant.

3) Participating in the tasks on the crowdsourcing intermediary platform lets me feel a sense of person achievement.

4) crowdsourcing intermediary platform gives me a chance to do things I am good at.

\section{Trust in the task requester (RT)}

1) Task requesters on the crowdsourcing intermediary platform are in general dependable.

2) Task requesters on the crowdsourcing intermediary platform are in general reliable.

3) Task requesters on the crowdsourcing intermediary platform are in general honest.

4) Task requesters on the crowdsourcing intermediary platform are in general trustworthy.

\section{Work effort (WE)}

1) I focus my attention on completing tasks which I am participating in on the crowdsourcing intermediary platform.

2) I frequently think about the tasks which I am participating in on the crowdsourcing intermediary platform *.

3) I work at my full capacity to finish the task which I am participating in on the crowdsourcing intermediary platform.

4) I try hard to finish the task which I am participating in on the crowdsourcing intermediary platform 
5)I put a lot of effort into completing tasks which I am participating in on the crowdsourcing intermediary platform.

6) I never give up trying to finish the task which I am participating in on the crowdsourcing intermediary platform.

7) I persist in overcoming obstacles to complete the task which I am participating in on the crowdsourcing intermediary platform.

8) I am strongly committed to pursuing the goal of finishing the task which I am participating in on the crowdsourcing intermediary platform.

Notes: * represents this item has been deleted in the data analysis. 